\title{
Flexural properties of all bamboo "green" composites
}

\author{
H. Takagi, A. Mizobuchi, K. Kusano \& Y. Okitsu \\ Institute of Technology and Science, The University of Tokushima, Japan
}

\begin{abstract}
This paper deals with the development and evaluation of environment-friendly composites that are composed of only bamboo. Japanese timber bamboo (Madake) is hot pressed in order to increase its mechanical properties, such as flexural strength and impact strength. The hot pressing conditions are varied from room temperature to $220^{\circ} \mathrm{C}$. The flexural strength, flexural modulus, compressive strength and Izod impact strength increase with increasing the moulding temperature up to $160^{\circ} \mathrm{C}$, showing the maximum peak values. The effect of moulding pressure on the mechanical properties is smaller than the effect of the moulding temperature. Extensive densification in both the vascular bundle and parenchyma cell regions is achieved by hot pressing and this increase in density results in the increased mechanical properties.
\end{abstract}

Keywords: green composites, natural fibre composites, bamboo, hot press, densification, flexural strength, impact strength.

\section{Introduction}

Bamboo is recognized to be a high-strength and flexible natural material from the viewpoint of industrial materials [1-3]. Since the bamboo has a hollow structure with joints, it is has been applied to fishing rods, flagpoles and scaffold materials. In addition to that, the growth speed of bamboo is much faster than that of woods, for example it reaches 15 to $20 \mathrm{~m}$ in height within only one year. Therefore rapid environmental repair after extensive cutting is possible in a shorter period than with wood, which requires many years for regeneration. Therefore, the potential of bamboo to be a sustainable engineering material has been anticipated in recent years in Japan. 
In comparison with glass fibre-reinforced plastics (GFRP), which are now used abundantly, the mechanical characteristics of bamboo are inferior. Furthermore, as described above, since the bamboo has a hollow structure, it is impossible to fabricate a wide and thick plate directly from a raw bamboo column. In general, it well known that the mechanical properties of wood is strongly affected by its density, thus there is a possibility of increasing the strength of bamboo by an adequate consolidation process.

Research on the structure of bamboo has been carried out, and it has been clarified that the inherent strong and stiff characteristics of bamboo are derived from long bamboo fibres that are unidirectionally aligned in the bamboo column. Zhang et al. [4] have made a composite material composed of bamboo strip and aluminium plate, and reported their improved mechanical properties. Shito et al. [3] have developed biodegradable composite material that was fabricated by combining biodegradable resin and mechanically extracted bamboo fibres. Takagi and Ichihara [5] have also developed a starch-based biodegradable composite material reinforced by high strength bamboo fibres extracted by a steam explosion method.

In this study, we applied uniaxial hot press processing to Japanese timber bamboo, Madake, in order to obtain high strength bio-based "green" composite materials, which can be applied to a wood bonding material (nail). Then, the effect of hot pressing conditions on the mechanical properties of hot pressed bamboo was examined.

\section{Materials and experimental methods}

\subsection{Raw material}

Japanese timber bamboo (Phyllostachys bambsoides), estimated at 2-4 years old, collected in Hyogo Prefecture, Japan was used in this experiment. Takagi et al. [6] have reported that bamboo and the strength of the bamboo fibre changes depending on the specimen's height above the ground when collected. In this experiment, a bamboo specimen taken from within $2 \mathrm{~m}$ above the ground was used in order to avoid such a change in strength.

The bamboo strip of $10 \times 200 \mathrm{~mm}$ without joints was shaved out from collected bamboo with a saw and a planer. The bamboo strip sample trip soaked in tap water was stored in a refrigerator kept at $5^{\circ} \mathrm{C}$. All the samples were dried at $50^{\circ} \mathrm{C}$ for 22 hours just before hot pressing in order to reduce the effect of water content of sample on consolidation behaviour. After this drying process, the water content of the sample before moulding was kept at $5 \pm 3 \mathrm{wt} . \%$.

\subsection{Hot pressing}

The hot press moulding was carried out using a hot pressing machine (MC-16EF, Imoto Machinery Co. Ltd., Japan), after setting the bamboo sample in a specially designed metallic mould (punch dimension: $10 \times 200 \mathrm{~mm}$ ). The moulding temperature was changed from room temperature to $220^{\circ} \mathrm{C}$, in order to 
investigate the effect of moulding conditions on the mechanical properties of bamboo composites. However the moulding pressure and time was fixed to 50 $\mathrm{MPa}$ and 10 minutes, respectively.

\subsection{Flexural testing}

The 3-point flexural test was carried out using a universal testing machine (Model 5567, Instron, U.S.A.) at room temperature. The dimensions of the specimen are $10 \mathrm{~mm}$ width and $100 \mathrm{~mm}$ length. The thickness of the specimen was $3-5 \mathrm{~mm}$, which varied with the hot pressing conditions. The flexural test was carried out under the following conditions: test speed of $1.0 \mathrm{~mm} / \mathrm{min}$ and span length of $50.0 \mathrm{~mm}$. During the test, the outer surface of the bamboo composites specimen was always set to be in a tensile condition.

\subsection{Impact testing}

An Izod impact test with unnotched specimens was performed at room temperature by using an Izod impact tester (No. 158, Yasuda Machine Factory Co. Ltd., Japan) with a $5.05 \mathrm{~J}$ hammer. During the test, the outer surface of the bamboo composites specimen was always set to be hit by the hammer.

\section{Experimental results and discussion}

\subsection{The effect of moulding temperature on flexural properties}

The results of flexural tests for bamboo green composites moulded at $50 \mathrm{MPa}$ and at different temperatures from room temperature to $220^{\circ} \mathrm{C}$ are shown in figs. $1-3$. Figures 1-3 correspond to the results of flexural strength, flexural modulus,

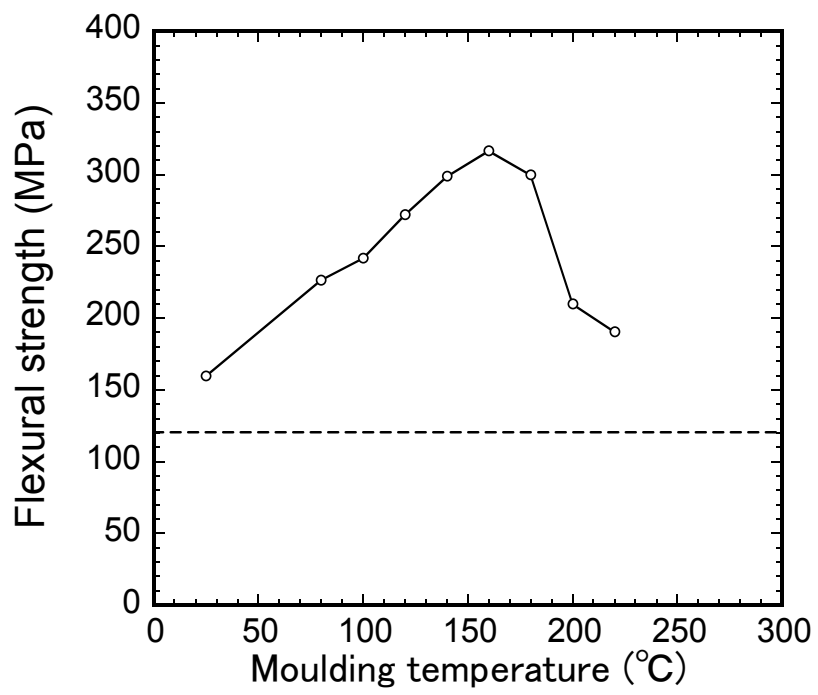

Figure 1: $\quad$ Flexural strength as a function of moulding temperature. 


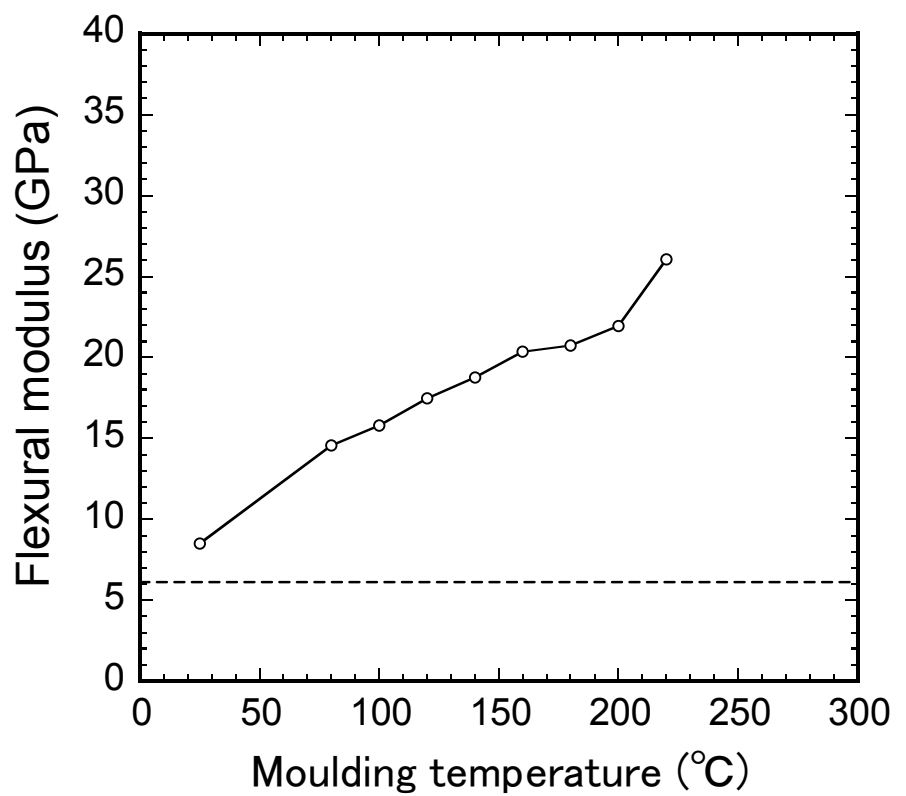

Figure 2: $\quad$ Flexural modulus as a function of moulding temperature.

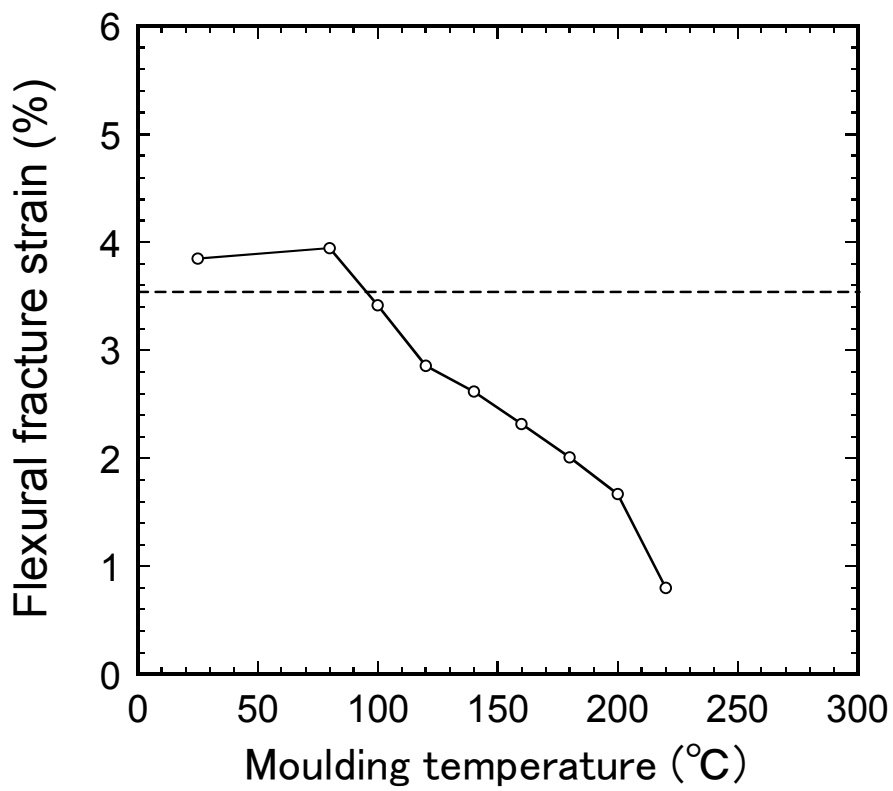

Figure 3: $\quad$ Flexural fracture strain as a function of moulding temperature. 
and flexural fracture strain, respectively. The broken line in these figures shows the result for the unmoulded bamboo. The flexural strength increases with increasing the moulding temperature, and indicates a peak flexural strength of $320 \mathrm{MPa}$ at the moulding temperature ranges near $160^{\circ} \mathrm{C}$. The maximum flexural strength of $315 \mathrm{MPa}$ is correspondent to 2.7 times the strength of the un-moulding bamboo, and it can be seen that the remarkable strengthening is possible by applying the hot press moulding.

There is an almost linear relationship between flexural modulus and moulding temperature as shown in fig. 2. The flexural modulus of the bamboo composites moulded at $220^{\circ} \mathrm{C}$ reaches over $25 \mathrm{GPa}$, and it can be seen that this flexural modulus value is comparable to that of the GFRP strengthened by glass fibres. The bamboo composites moulded at temperatures lower than $80^{\circ} \mathrm{C}$ have almost the same flexural fracture strain as that of un-moulded bamboo as shown in figure 3. However, the flexural fracture strain decreases with the rise of moulding temperatures above $80^{\circ} \mathrm{C}$.

\subsection{The effect of moulding temperature on impact strength}

Figure 4 shows the results of Izod impact strength of bamboo composites moulded at different temperatures. It is proven from fig. 4 that Izod impact strength also shows a similar dependence of flexural strength with moulding

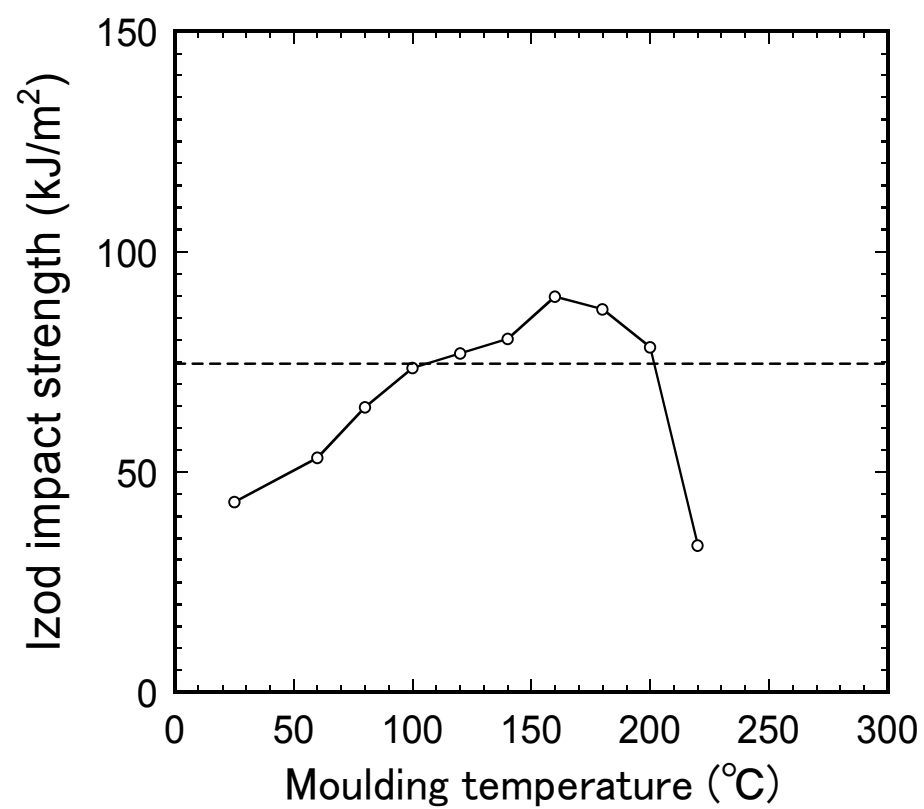

Figure 4: Izod impact strength as a function of moulding temperature. 
temperature. However, it can be seen that Izod impact strength becomes lower than the value of unmoulded material, as indicated in a broken line in the figure, when the bamboo composites were moulded at room temperature.

\subsection{The effect of moulding temperature on sample density}

The relationship between sample density and moulding temperature is shown in fig. 5. The sample density increases almost linearly with moulding temperature, and the moulding up to $50 \mathrm{MPa}$ will increase the sample density by 1.4 times even at room temperature. Sample density (fig. 5), flexural strength (fig. 1), flexural modulus (fig. 2), and Izod impact strength (fig. 4) have qualitatively the same moulding dependence, i.e., these increases in mechanical properties seem to be attributed to the increases in density. In addition, this type of improvement in mechanical properties by densification has also been confirmed in other wood-based materials [7,8]. It can be seen from the observation of internal microstructure that extensive densification at both the vascular bundle and parenchyma cell regions was achieved by hot pressing and that this increase in density results in the increased mechanical properties.

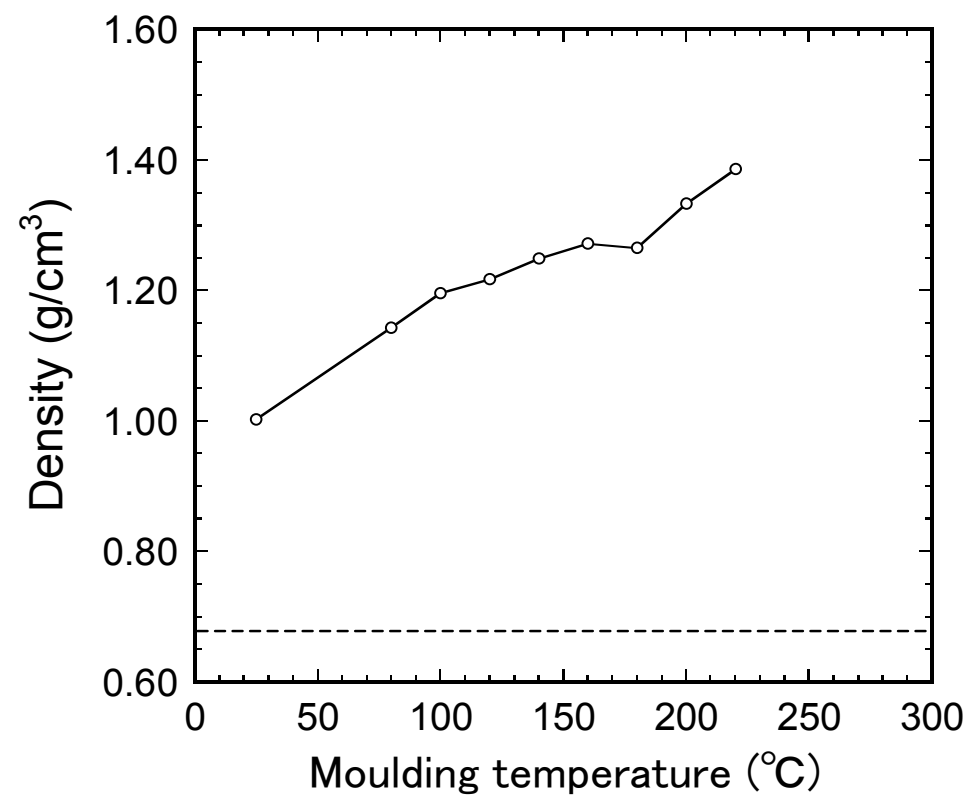

Figure 5: $\quad$ Sample density as a function of moulding temperature.

\section{Conclusions}

The flexural properties of all bamboo green composites fabricated by a hot pressing method were investigated. The major results obtained are summarized as follows: 
1) High strength bamboo "green" composites can be made by hot pressing. Their strength is comparable to that of GFRP.

2) The optimum moulding temperature is $160^{\circ} \mathrm{C}$ among the conditions investigated.

3) The maximum flexural strength and flexural modulus obtained are $320 \mathrm{MPa}$ and $25 \mathrm{GPa}$, respectively. This maximum flexural strength is almost 2.7 times as large as that of unmoulded bamboo.

4) Extensive densification in both the vascular bundle and parenchyma cell regions is achieved by hot pressing and this increase in density results in the increased mechanical properties.

\section{References}

[1] Oda, J., Morphological analysis of bamboo from the viewpoints of engineering, Transactions of the Japan Society of Mechanical Engineers. A, 46(409), pp. 997-1006, 1980.

[2] Amada, S., Ichikawa, Y., Munekata, T., Nagase, Y. \& Shimizu, H., Fiber texture and mechanical graded structure of bamboo, Composites Part B, 28(1-2), pp. 13-20, 1997.

[3] Shito, T., Okubo, K. \& Fujii, T., Development and mechanical properties eco-composites using bamboo fiber, Bamboo Journal, 19, pp. 15-23, 2002.

[4] Zhang, J. Y., Zeng, Q. Y. Z., Yu, T. X. \& Kim, J. K., Residual properties of reformed bamboo/aluminium laminates after hygrothermal aging, Composites Science and Technology, 61(8), pp. 1041-1048, 2001.

[5] Takagi, H. \& Ichihara, Y., Effect of fiber length on mechanical properties of "green" composites using a starch-based resin and short bamboo fibers, JSME International Journal Series A, 47, pp.551-555, 2004.

[6] Takagi, H, Takura, R., Ichihara, Y., Ochi, S., Misawa, H. \& Niki, R., The mechanical properties of bamboo fibers prepared by steam-explosion method, Journal of The Society of Materials Science, Japan, 52(4), pp. 353356, 2003.

[7] Ito, Y., Tanahashi, M., Shigematsu, M., Shinoda, Y. \& Ohta, C., Compressive-molding of wood by high-pressure steam-treatment: part 1 . development of compressively molded squares from thinnings, Holzforschung, 52(2), pp. 211-216, 1998.

[8] Inoue, M. \& Norimoto, M., Possibilities of bamboo based high strength materials, Proceedings of the 5th International Wood Science Symposium, p. 402, 2004. 